7. Reprod. Fert. (1972) 29, 425-429

\title{
THE EFFECT OF SEASONS ON THE SPERM DIMENSIONS OF BUFFALO BULLS
}

\author{
K. P. PANT* AND D. P. MUKHERJEE \\ Division of Animal Genetics, Indian Veterinary Research Institute, Izatnagar, India
}

(Received 13th November 1971, accepted 11th Fanuary 1972)

\begin{abstract}
Summary. Dimensional characteristics and proportions of live spermatozoa in permanent nigrosin-eosin preparations from the semen samples of Murrah buffalo bulls were studied in different seasons. Between bulls, all the characteristics varied significantly. Between seasons, all the characteristics, except length of head and mid-piece, varied significantly. Environmental temperature and humidity both appeared to influence the dimensional and enumeration characteristics of the spermatozoa. The percentage of live spermatozoa decreased with increase in air temperature and humidity.
\end{abstract}

There is ample evidence that the dimensional characteristics of the spermatozoa of various species are under genetic control; a review on the subject has been published recently (Beatty, 1970). In tropical bulls, the seasons have been shown to influence the sperm dimensions (Mukherjee \& Singh, 1966; Mishra, Singh \& Roychoudhury, 1969), and the reproductive performance of buffaloes is known to be more influenced by the seasons than that of other cattle. In the present study, buffalo spermatozoa were studied in four seasons for the following characteristics: head length, breadth, area and shape (head length/head breadth), mid-piece length, breadth and area and the proportion of unstained spermatozoa.

The semen samples from four Murrah buffalo bulls were collected at an interval of 3 days during the peaks of the seasons (December to January-Winter; February to March-Spring; May to June-Summer; August-Autumn). Sixteen samples, four in each season from each bull, were examined. From each sample, three permanent nigrosin-eosin (Hancock, 1951) preparations were made on clean grease-free slides. The 192 slides were coded and the code was not available until all the observations had been made on the spermatozoa. In each slide, four unstained and morphologically normal spermatozoa were randomly selected and camera lucida drawings of the head and the midpiece of these spermatozoa were made on separate sheets of paper at a linear magnification of $\times 5975$. It has already been shown (Beatty \& Sharma, 1960) that mean differences smaller than the limits of optical resolution can be validly studied. From the measurements on four spermatozoa, made by the method of Rajwar \& Mukherjee (1970), the averages of each characteristic were calculated

* Present address: Institute of Animal Genetics, West Mains Road, Edinburgh EH9 3JN. 


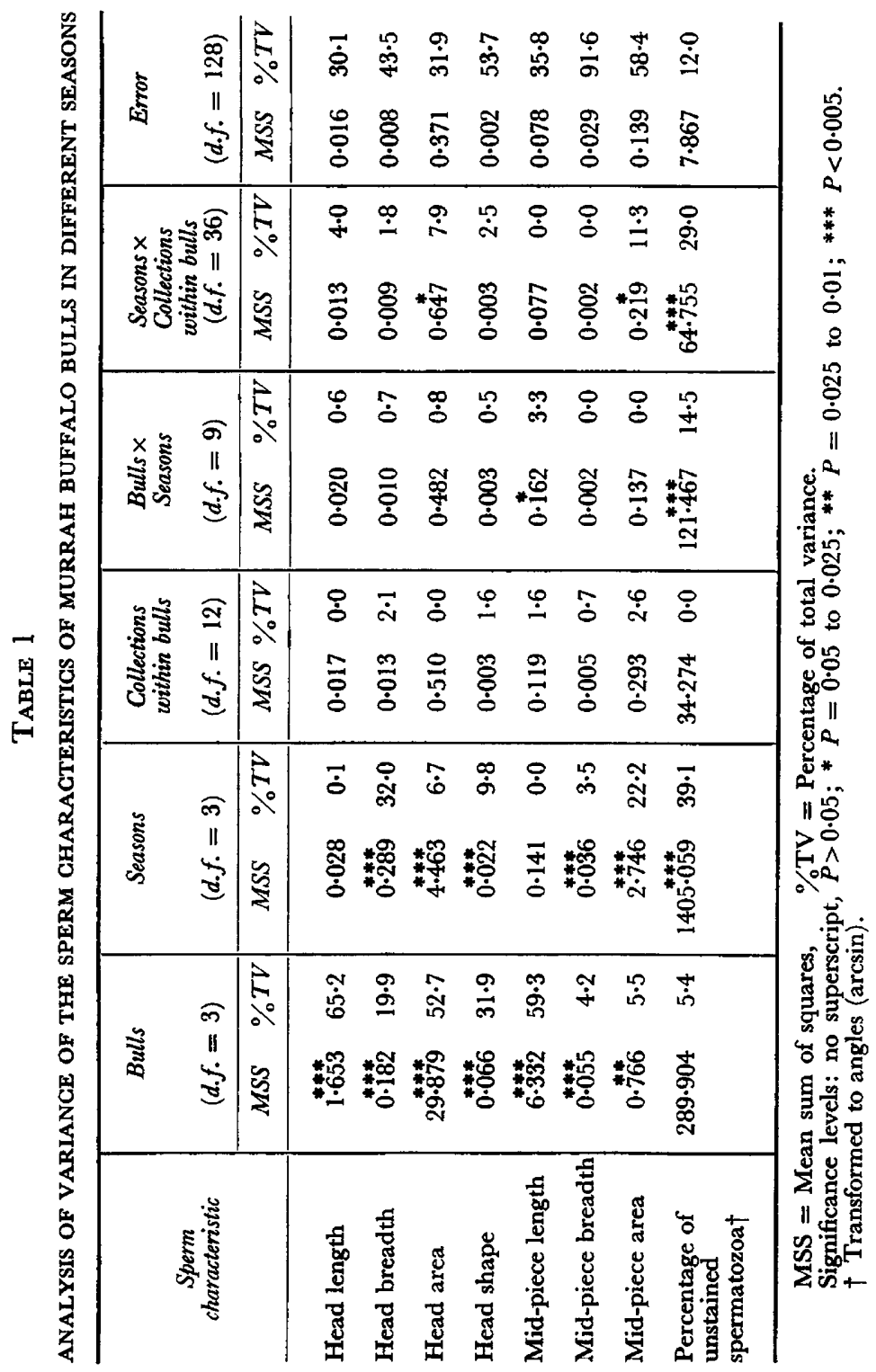




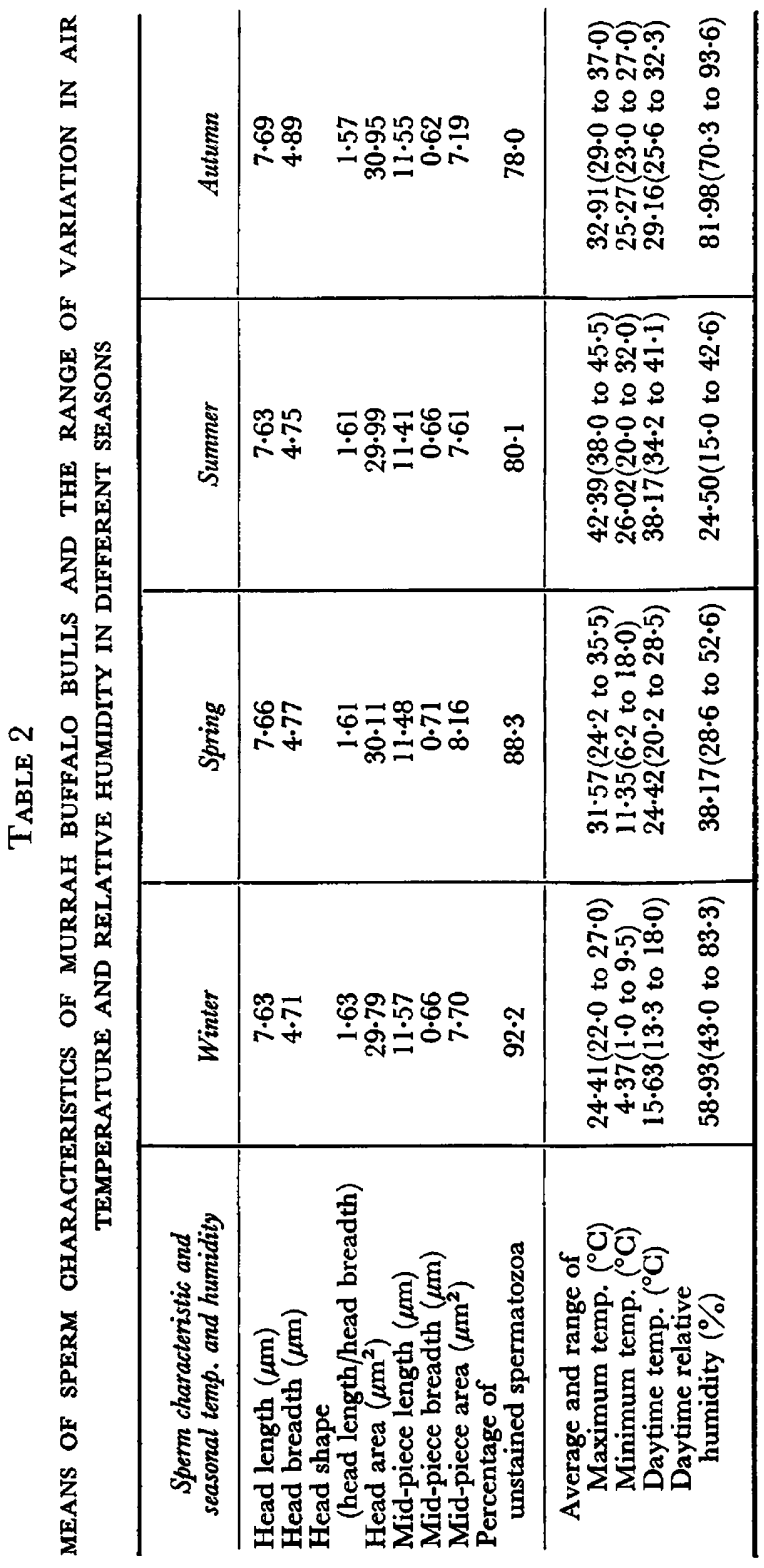


for each slide. These averages were then studied by analysis of variance and the results were finally converted to $\mu \mathrm{m}$ and $\mu \mathrm{m}^{2}$. The percentage of unstained spermatozoa was scored by counting 100 randomly selected spermatozoa in each slide and analysed after angular transformation. In the analysis, source of variation was partitioned as shown in Table 1. Mean squares (MS) between bulls was tested against the Bulls $\times$ Seasons interaction. To test the MS between collections within bulls, the interaction MS between seasons and collections within bulls was used. To test the MS between seasons, no single interaction was found to be a valid error term. Composite MS for seasons as well as for error and their respective degrees of freedom were therefore computed according to the method of Johnson \& Keeping (1952).

Analysis of variance and percentage variance components are given in Table 1. All the mensuration characteristics of spermatozoa varied significantly between bulls. The percentage of unstained spermatozoa, however, showed no significant variation between bulls. The bulls used in the present experiment were selected on the basis of semen quality tests (including unstained sperm percentage), and this may be responsible for the reduced variation between bulls. All the sperm characteristics, except length of head and length of midpiece, varied between seasons. A comparison of variance components shows that the variation between seasons was greater than between bulls in the head breadth, mid-piece area and the proportion of unstained spermatozoa. Midpiece breadth was equally influenced by the seasons and the bulls. The head area varied more between bulls than between seasons.

The means of the sperm characteristics in different seasons are given in Table 2. The head breadth and head area were minimal during winter and maximal during autumn when the air temperature was almost as high as in summer and was associated with very high relative humidity. As a result of the change in the head breadth, head shape was minimal during autumn and maximal during winter. Between spring and winter, the characteristics of the head did not vary. It appears, therefore, that with the increase in atmospheric temperature, the sperm head tended to become broader and this change was more marked in autumn when the relative humidity ranged between $70 \%$ and $94 \%$. Thus, relative humidity seems to influence the sperm dimensions of buffaloes. Mukherjee \& Singh (1966) reported no effect of relative humidity on the sperm dimensions of Hariana bulls.

The mid-piece breadth and area were minimal in autumn and maximal in spring. Between summer and winter, these characteristics did not vary. From all the studies that have been made on various animals, it is now clear that the mid-piece length is relatively free of environmental influence. Its heritability in mouse has been shown to vary between $76 \%$ and $97 \%$ (Woolley \& Beatty, 1967; Woolley, 1970).

A decrease in the proportion of unstained spermatozoa with an increase in air temperature and humidity is expected in view of several reports including those of Waites \& Setchell (1964), and Moule \& Waites (1963). However, this decrease is much greater than that reported by Mukherjee \& Singh (1966) for the proportions of unstained spermatozoa at different seasons in Hariana bulls. 
One of us (K.P.P.) is grateful to the Indian Council of Agricultural Research, New Delhi, for financial assistance.

\section{REFERENCES}

BEATty, R. A. (1970) The genetics of the mammalian gamete. Biol. Rev. 45, 73.

Beatty, R. A. \& Sharma, K. N. (1960) Genetics of gametes. III. Strain differences in spermatozoa from eight inbred strains of mice. Proc. R. Soc. Edinb. B, 68, 25.

HANCOCK, J. L. (1951) A staining technique for the study of temperature shock in semen. Nature, Lond. $167,323$.

Johnson, L. P. V. \& Keeping, E. S. (1952) Composite mean squares and their degrees of freedom. Appl. Statist. 1, 202. (cf. Johnson, L. P. V. (1963) Biometrical methods, p. 143. Institute for the Advancement of Science and Culture, New Delhi.)

Mishra, H. R., Singh, R. L. \& Roychoudhury, P. N. (1969) Seasonal variations in spermatozoan characteristics of Tharparkar and Hariana bulls. Zootec. Vet. 24, 274.

Moule, G. R. \& Wartes, G. M. H. (1963) Seminal degeneration in the ram and its relation to the temperature of the scrotum. F. Reprod. Fert. 5, 433.

MuKherJeE, D. P. \& Singh, S. P. (1966) Seasonal variations in the characteristics of bull spermatozoa. Indian F. vet. Sci. 36, 104.

Rajwar, B. M. S. \& MukherjeE, D. P. (1970) Studies on the cytomorphology of spermatozoa in homo- and heterospermic semen of bulls (Bos indicus L.) and buffalo-bulls (Bubalus bubalis L.). II. Effect of temperature shock at $5^{\circ} \mathrm{C}$ and $30^{\circ} \mathrm{C}$ on the enumeration and mensuration characteristics of live spermatozoa. Indian 7. Anim. Sci. 40, 557.

Wartes, G. M. H. \& Setchell, B. P. (1964) Effect of local heating on blood flow and metabolism in the testis of the conscious ram. F. Reprod. Fert. 8, 339.

WoollEY, D. M. (1970) Selection for the length of the spermatozoan midpiece in the mouse. Genet. Res. 16, 261.

Woolley, D. M. \& BeATTY, R. A. (1967) Inheritance of midpiece length in mouse spermatozoa. Nature, Lond. 215, 94. 